\title{
Emerging Role of Proteases in the Pathogenesis of Chronic Rhinosinusitis with Nasal Polyps
}

\author{
Dawei Wu ${ }^{1,2}$, Yongxiang $W_{e}{ }^{2}$ and Benjamin S. Bleier ${ }^{1 *}$ \\ ${ }^{1}$ The Department of Otolaryngology, Massachusetts Eye and Ear Infirmary, Harvard Medical School, Boston, MA, \\ United States, ${ }^{2}$ The Department of Otorhinolaryngology, Beijing Anzhen Hospital, Capital Medical University, Beijing, China
}

OPEN ACCESS

Edited by:

Richard George Douglas, University of Auckland, New Zealand

Reviewed by:

Simon Carney,

Flinders University, Australia

Eui-Cheol Shin,

KAIST, South Korea

*Correspondence:

Benjamin S. Bleier

benjamin_bleier@meei.harvard.edu

Received: 04 October 2017 Accepted: 26 December 2017 Published: 12 January 2018

Citation:

Wu D, Wei Y and Bleier BS (2018) Emerging Role of Proteases in the Pathogenesis of Chronic Rhinosinusitis with Nasal Polyps. Front. Cell. Infect. Microbiol. 7:538. doi: 10.3389/fcimb.2017.00538
Chronic rhinosinusitis with nasal polyps (CRSwNP) is a heterogeneous upper airway disease with multiple etiologies. Clinically, CRSwNP can be classified into either eosinophilic or non-eosinophilic subtypes. The eosinophilic phenotype of CRSWNP is widely thought to be highly associated with recurrence of nasal polyps or surgical failure. Epithelial cells have a crucial role in the development of Th2-biased airway diseases. Recent studies have shown that a wide range of external stimuli such as allergens and microorganisms can elicit the release of epithelial-derived Th2-driving cytokines and chemokines. Protease activity is a feature common to these multiple environmental insults and there is growing evidence for the concept that an imbalance of proteases and protease inhibitors in the epithelial barrier leads to both the initiation and maintenance of chronic eosinophilic airway inflammation. In this review, we analyze recent work on the role of proteases in the development of the sinonasal mucosal type 2 immune response with an emphasis on the molecular pathways promoting adaptive Th2 cell immunity.

Keywords: chronic rhinosinusitis, nasal polyps, eosinophil, protease, epithelium

\section{INTRODUCTION}

Chronic rhinosinusitis is a chronic inflammatory upper airway disease characterized by 12 weeks of typical symptoms including nasal discharge, congestion, facial pressure or pain, and olfactory disorder (Fokkens et al., 2012). Chronic rhinosinusitis with nasal polyps (CRSwNP), a multifactorial and highly heterogeneous upper airway disease, is a severe phenotype of chronic rhinosinusitis and presents with distinct immunological and histopathological features compared with chronic rhinosinusitis without nasal polyps (CRSsNP).

Despite aggressive medical therapy or radical endoscopic sinus surgical treatment, many patients with CRSwNP tend to be poorly controlled and have a high recurrence rate (Wynn and Har-El, 2004; Mendelsohn et al., 2011; Baguley et al., 2014; DeConde et al., 2017). Several factors which associate with a worse outcome or recurrence risk have been identified, such as high tissue eosinophil infiltration, more severe preoperative disease (i.e., a higher CT score), and a series of comorbid disease (i.e., aspirin-exacerbated respiratory disease (AERD), allergic asthma and cystic fibrosis) (Desrosiers, 2004; Tosun et al., 2010; Mortuaire et al., 2015; Ta and White, 2015; Tipirneni and Woodworth, 2017; Wu et al., 2017).

Clinically, CRSwNP is classified into two phenotypes based on the dominant inflammatory cell type in tissues: eosinophilic CRSwNP (ECRSwNP) and non-eosinophilic CRSwNP (NECRSwNP) (Cao et al., 2009; Shah et al., 2016; Wu et al., 2016; Cho S.-W. et al., 2017). In western countries, the majority of patients with CRSwNP (80-88\%) have prominent tissue eosinophilia, edema formation, 
and a type 2 helper T-cell (Th2) dominant immune response (Bateman et al., 2005; Fokkens et al., 2005; Van Zele et al., 2006). CRSwNP may be associated with asthma and aspirin intolerance (Fokkens et al., 2012; Stevens et al., 2017). However, at least half of patients with CRSwNP in East Asian countries including China, Korea and Japan have a non-eosinophilic phenotyps of nasal polyps characterized by Th1/Th17-dominant inflammation (Kim et al., 2007; Zhang et al., 2008; Cao et al., 2009; Ikeda et al., 2013).

The past decade has witnessed a change in the understanding of mechanisms underlying eosinophilic airway diseases from a paradigm in which allergen-independent, e.g., Th2 cells are the primary drivers, to one in which production of epithelialderived chemokines and cytokines by dysfunctional respiratory epithelium are the primary orchestrators of the eosinophilic immune response (Hammad and Lambrecht, 2015; Pfeffer and Corrigan, 2017). A large range of both endogenous and extrinsic stimuli can activate the epithelial cell and elicit the release of epithelial-derived chemokines and cytokines which, in turn, induce the type 2 immune response (Hammad and Lambrecht, 2015; Schleimer and Berdnikovs, 2017). External stimuli, including allergen, fungus, Staphylococcus aureus and microbiome disturbance have been posited as significant contributing factors in CRSwNP pathophysiology and have been implicated in driving Th2-biased airway disease (Sachse et al., 2010; Clark et al., 2013; Madeo and Frieri, 2013; Ou et al., 2014; Lan et al., 2016; Orlandi et al., 2016; Tomassen et al., 2016; Schleimer, 2017).

Protease activity is a common unifying feature of many of these environmental insults suggesting an underlying common etiopathogenesis (Sokol et al., 2008; Gregory and Lloyd, 2011; Stentzel et al., 2017; Teufelberger et al., 2017). Airborn allergens, such mites, pollen, as well as microorganisms, such as bacteria, rhinovirus, and influenza virus, and fungi are major sources of exogenous proteases (Reed and Kita, 2004; Sokol et al., 2008; Costenaro et al., 2011; Takai and Ikeda, 2011; Kesic et al., 2012). The innate immune response to these exogenous proteases seems to play a crucial role during the development of Th2biased immune response (Kamijo et al., 2013; Hara et al., 2014; Snelgrove et al., 2014; Teufelberger et al., 2017). It therefore follows that an imbalance of proteases and protease inhibitors in the epithelial barrier may lead to the initiation and maintainancc of eosinophilic inflammation in CRSwNP and therefore be a central driver of eosinophilic airway disease (Kouzaki et al., 2017; Pfeffer and Corrigan, 2017).

This review will summarize the current knowledge on the role of proteases during the development of the sinonasal mucosal type 2 immune response, with an emphasis on the molecular pathways initiating the innate type 2 cell response and then promoting adaptive Th2 cell immunity. This is followed by a discussion of the dysfunctional regulation

\footnotetext{
Abbreviations: CRSwNP, Chronic rhinosinusitis with nasal polyps; CRSsNP, chronic rhinosinusitis without nasal polyps; ECRSwNP, eosinophilic chronic rhinosinusitis with nasal polyps; NECRSwNP, non-eosinophilic chronic rhinosinusitis with nasal polyps; Th2, type 2 helper T-cell; PARs, proteaseactivated receptors; TLR4, toll-like receptor 4; ZO-1, Zonula occludens-1; HDM, house dust mite; SpID, serine protease like protein D; FCPs, fibrinogen cleavage products; P-gp, P-glycoprotein.
}

of proteases and proteases inhibitors in the epithelial barrier.

\section{Mechanisms of the Activation of the Airway Epithelial Cells upon External Protease Exposure}

Cysteine and or serine proteases occur in some groups of airborne mite, pollen, cockroach, fungi, and Staphylococcus aureus (Asokananthan et al., 2002; Reed and Kita, 2004; Jacquet, 2011; Takai and Ikeda, 2011; Balenga et al., 2015; Kale et al., 2017; Stentzel et al., 2017; Teufelberger et al., 2017). Allergen derived proteases interact with epithelial cells through three principle pathways: direct effects on junctional proteins, reacting with cell surface protease-activated receptors (PARs), and toll-like receptor 4 (TLR4)-dependent epithelial activation. An integrated mechanism is summarized and illustrated in Figure 1.

Allergen source-derived proteases (both cysteine and serine protease) can directly degrade tight junctions in the epithelium (Wan et al., 1999, 2001; Tai et al., 2006; Runswick et al., 2007; Hirasawa, 2010; Kale et al., 2017) and increase the accessibility of microorganisms and antigens to the underlying lamina propria and connective tissue thereby triggering strong innate immune responses to allergens (Gregory and Lloyd, 2011). It has been reported that the levels of occludin, E-cadherin, and zonula occludens-1 (ZO-1) were all reduced in mature polyps derived from patients with CRSwNP. Moreover, aquaporin 5, a marker of epithelial differentiation, was obviously reduced in sinonasal samples of patients with CRSwNP when compared with levels in CRSsNP or control subjects (Shikani et al., 2014).

Apart from direct effects on junctional epithelial proteins, environmental proteases can interact with PARs in the airway to stimulate the proliferation and migration of innate and adaptive leukocytes (Reed and Kita, 2004). PARs are a novel family of seven-transmembrane $G$ protein-coupled receptors that are widely expressed in human airway epithelium. There are four types of PARs (PAR1, PAR2, PAR3, and PAR4) which play an integral role in defending against environmental proteases (Coughlin and Camerer, 2003; Reed and Kita, 2004). Several reports have linked PAR activation to the allergic immune response (Kheradmand et al., 2002; Jacquet, 2011). Exogenous proteases from house dust mite (HDM), cockroach or Alternaria alternate were shown to play an important role in allergy development, partly by activating PAR2 signaling in the epithelial cells (de Boer et al., 2014). In CRSwNP, airborne fungal proteases can activate both PAR2 and PAR-3 leading to the proliferation and migration of inflammatory cells (Shin et al., 2006). Furthermore, the level of the PAR-2 in cultured primary nasal epithelial cells and nasal polyps from patients with ECRSwNP was significantly increased as compared with NECRSwNP and controls (Kouzaki et al., 2016). However, in patients with allergic fungal rhinosinusitis, only PAR-3 showed statistically significant differential expression compared to non-diseased controls (Ebert et al., 2014). 


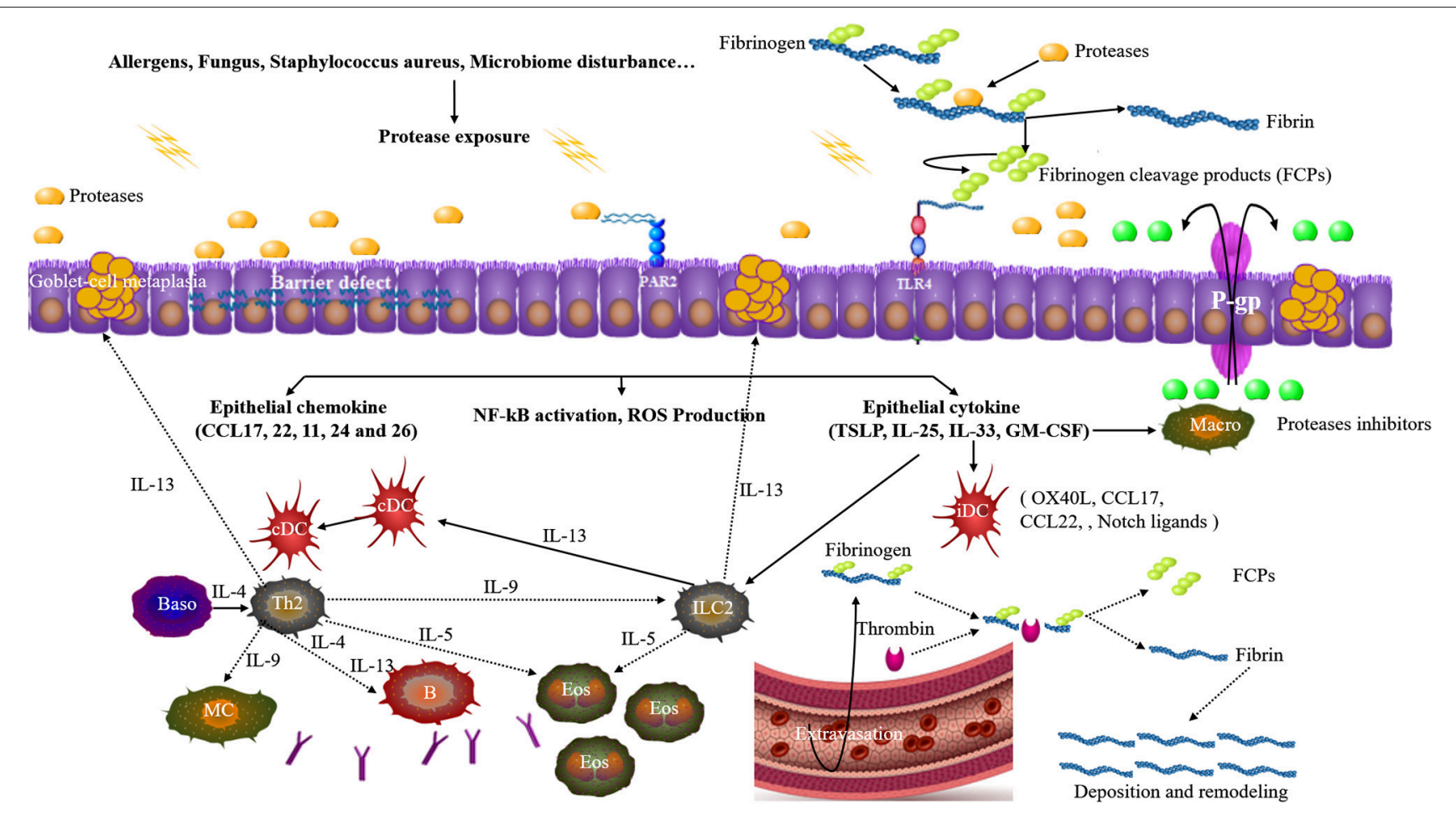

FIGURE 1 | Upon allergen proteases exposure, junctional proteins among epithelial cells are disrupted. Allergen proteases can directly react with protease-activated receptor 2 (PAR2). Allergen proteases cleave the serum factor fibrinogen, thus releasing fibrinogen cleavage products (FCPs) which can activate toll-like receptor 4 (TLR4). Epithelial cells get activated to produce and release pro-Th2 cell chemokines and cytokines which instruct immature dendritic cells (iDC) and activate ILC2s. Additionally, the activation of these receptors will also induce NF-kB activation, ROS production. Th2 cells and ILC2s are activated and promote the eosinophilia, production of lgE and goblet-cell metaplasia. Allergen exposure is generally accompanied by fluid extravasation and thrombin also generates FCPs from fibrinogen, thus triggering TLR4. P-glycoproteins (P-gp) in the epithelial cells promote the efflux of protease inhibitors to suppress the allergen proteases. $c D C$ classical DC, Macro macrophage, Baso basophils, MC mast cell.

Staphylococcus aureus is a versatile bacteria frequently found colonizing patients with Th2-biased diseases such CRSwNP and asthma (Bachert et al., 2010; Sachse et al., 2010). Several endotypes of chronic rhinosinusitis have been identified based on the presence of $S$. aureus enterotoxin(SE)- specific IgE (Bachert and Akdis, 2016; Tomassen et al., 2016). The presence of SE-specific IgE associates with intense eosinophilic inflammation in CRSwNP, high IgE concentration and comorbid asthma (Bachert et al., 2010; Tomassen et al., 2016). Recently, serine protease like protein $\mathrm{D}(\mathrm{SplD})$ and other closely related proteases secreted by $\mathrm{S}$. aureus have been identified as inducers of allergic asthma in both humans and mice (Stentzel et al., 2017). Furthermore, SplD-induced Th2-biased inflammatory response and IgE production in the airway inflammation were largely dependent on the IL-33/ST2 axis and independent of TLR4 and PAR-2 signaling (Teufelberger et al., 2017).

TLR activation has been the subject of intense study with respect to its role in protease mediated airway inflammation. The coagulation system has been implicated in eosinophilic airway diseases, such as asthma and CRSwNP as a result of collagen deposition and airway remodeling, (Shimizu et al., 2011; Lambrecht and Hammad, 2013; Kim et al., 2015). Millien et al. found that activation of the coagulation cascade by allergenderived proteases is an important factor promoting asthmalike changes in mice. Allergen proteases can cleave the serum factor fibrinogen, thus releasing FCPs which directly activate TLR4 signaling (Millien et al., 2013). The development of an asthma-like condition caused by house-dust mites challenge relies on the expression of TLR4 on lower airway epithelial cells (Hammad et al., 2009). Furthermore, thrombin, the classic activator of coagulation, can also cleave fibrinogen into FCPs resulting in further upregulation of the TLR4 pathway. A recent study identifies a programmed cell death 1 ligand $2^{+}\left(\mathrm{PD}_{\mathrm{L} 2}{ }^{+}\right)$DC phenotype which accounts for the induction of Th2 cell response upon protease allergens exposure and fibrinogen-cleavage products can promote the generation of $\mathrm{PD}^{-} 2^{+}$DC through TLR4 (Cho M. et al., 2017). These studies suggest that TLR4 plays a critical role in the allergic response upon exposure to exogenous proteases.

A study by Seung-Heon Shin et al. showed that airborne fungi induced the activation of nasal polyp epithelial cell and TLR expression (TLR2, TLR3 and TLR4). Cytokine production was, in turn, suppressed by protease inhibitors and anti-TLR4 antibodies (Shin and Lee, 2010). 


\section{Imbalance and Dysfunctional Regulation of Proteases and Proteases Inhibitors in the Epithelial Barrier of CRSwNP}

Recently, a study showed that an imbalance of proteases and protease inhibitors within the epithelial barrier contributes to the pathogenesis of eosinophilic chronic rhinosinusitis (Kouzaki et al., 2017). Barrier defects might be induced by damage to key proteins that comprise tight or adherent junctions secondary to increased or unopposed protease activity. These findings suggest that individual susceptibility to protease mediated inflammation may arise from the inability to adequately mitigate exogenous protease mediated epithelial damage. A recent review (Schleimer and Berdnikovs, 2017) suggested that cystatin A and SPINK5 (a cysteine and serine protease inhibitor, respectively) possess important roles in protecting the airway epithelium against environmental proteases. Furthermore, SPINK5 can protect PARs which are expressed on multiple cell types in the nasal epithelium from environmental proteases (Hershenson, 2007). Furthermore, SPINK5 is thought to regulate the function of numerous proteases that might compromise the barrier (Tieu et al., 2009). What's more, both human and animal studies have showed that SPINK5 mutations are associated with chronic inflammation in epithelium (Cookson, 2004; Moffatt, 2004).

P-glycoprotein (P-gp) has been reported as a key immunoregulator of eosinophilic inflammation in both CRSwNP and CRSsNP (Bleier et al., 2013; Feldman et al., 2013; Cheng and Bleier, 2016). Protease inhibitors have been reported to induce the expression of P-gp suggesting that an imbalance in the protease system may further exacerbate inflammation through

\section{REFERENCES}

Asokananthan, N., Graham, P. T., Stewart, D. J., Bakker, A. J., Eidne, K. A., Thompson, P. J., et al. (2002). House dust mite allergens induce proinflammatory cytokines from respiratory epithelial cells: the cysteine protease allergen, Der p 1, activates protease-activated receptor (PAR)-2 and inactivates PAR-1. J. Immunol. 169, 4572-4578. doi: 10.4049/jimmunol.169.8.4572

Bachert, C., and Akdis, C. A. (2016). Phenotypes and emerging endotypes of chronic rhinosinusitis. J. Allergy Clin. Immunol. Pract. 4, 621-628. doi: 10.1016/j.jaip.2016.05.004

Bachert, C., Zhang, N., Holtappels, G., De Lobel, L., van Cauwenberge, P., Liu, S., et al. (2010). Presence of IL-5 protein and IgE antibodies to staphylococcal enterotoxins in nasal polyps is associated with comorbid asthma. J. Allergy Clin. Immunol. 126, 962-968.e6. doi: 10.1016/j.jaci.2010.07.007

Baguley, C., Brownlow, A., Yeung, K., Pratt, E., Sacks, R., and Harvey, R. (2014). The fate of chronic rhinosinusitis sufferers after maximal medical therapy. Int. Forum Allergy Rhinol. 4, 525-532. doi: 10.1002/alr.21315

Balenga, N. A., Klichinsky, M., Xie, Z., Chan, E. C., Zhao, M., Jude, J., et al. (2015). A fungal protease allergen provokes airway hyperresponsiveness in asthma. Nat. Commun. 6:6763. doi: 10.1038/ncomms7763

Bateman, N., Shahi, A., Feeley, K. M., and Woolford, T. J. (2005). Activated eosinophils in nasal polyps: a comparison of asthmatic and non-asthmatic patients. Clin. Otolaryngol. 30, 221-225. doi: 10.1111/j.1365-2273.2005.00969.x

Bleier, B. S., Nocera, A. L., Iqbal, H., Hoang, J. D., Feldman, R. E., and Han, X. (2013). P-glycoprotein functions as an immunomodulator in healthy human primary nasal epithelial cells. Int. Forum Allergy Rhinol. 433-438. doi: 10.1002/alr.21166 the induction of P-gp expression(Perloff et al., 2000; Huang et al., 2001; Chandler et al., 2003; Zastre et al., 2009). Additionally, some protease inhibitors have been shown to function as P-gp substrates further strengthening the link between protease inhibitors and P-gp (Chaillou et al., 2002; Meaden et al., 2002) (Zhang and Benet, 1998). While disequilibrium of both P-gp expression and proteases inhibitors within the nasal mucosa may play an interrelated role in CRSwNP, further studies are needed to explore this possible function.

\section{Summary and Perspectives}

In patients with CRSwNP, exogenous allergen and microorganism derived proteases play a crucial role in the development of type 2 immune response at the mucosal surface. Through direct effects on junctional proteins, binding to cell surface PARs, TLR4-dependent epithelial activation, disruption of barrier function, and P-gp activation, proteases both initiate and maintain the inflammation characteristic of Th2 mucosal disease. It has been proposed that drugs targeting protease function (Verma et al., 2016) in nasal mucus to restore the balance between proteases and protease inhibitors (Pfeffer and Corrigan, 2017) may represent an important potential therapeutic strategy in patients with CRSwNP and other eosinophilic airway diseases. However, more studies are required to explore the exact role of the protease and protease inhibitor axis in CRSwNP.

\section{AUTHOR CONTRIBUTIONS}

DW drafted the manuscript. Both YW and BB reviewed the manuscript and provided revisions.

Cao, P.-P., Li, H. B., Wang, B. F., Wang, S. B., You, X. J., Cui, Y. H., et al. (2009). Distinct immunopathologic characteristics of various types of chronic rhinosinusitis in adult Chinese. J. Allergy Clin. Immunol. 124, 478-484.e2. doi: 10.1016/j.jaci.2009.05.017

Chaillou, S., Durant, J., Garraffo, R., Georgenthum, E., Roptin, C., Clevenbergh, P., et al. (2002). Intracellular concentration of protease inhibitors in HIV-1infected patients: correlation with MDR-1 gene expression and low dose of ritonavir. HIV Clin. Trials 3, 493-501. doi: 10.1310/0873-BVDP-AKAY-445U

Chandler, B., Almond, L., Ford, J., Owen, A., Hoggard, P., Khoo, S., et al. (2003). The effects of protease inhibitors and nonnucleoside reverse transcriptase inhibitors on p-glycoprotein expression in peripheral blood mononuclear cells in vitro. J. Acquir. Immune Defic. Syndr. 33, 551-556. doi: 10.1097/00126334-200308150-00001

Cheng, Y. S., and Bleier, B. S. (2016). Influence of P-glycoprotein function on chronic rhinosinusitis/nasal polyps pathophysiology. Adv. Otorhinolaryngol. 79, 38-47. doi: 10.1159/000445094

Cho, M., Lee, J. E., Lim, H., Shin, H. W., Khalmuratova, R., Choi, G., et al. (2017). Fibrinogen cleavage products and Toll-like receptor 4 promote the generation of programmed cell death 1 ligand 2-positive dendritic cells in allergic asthma. J. Allergy Clin. Immunol. doi: 10.1016/j.jaci.2017.09.019. [Epub ahead of print].

Cho, S.-W., Kim, D. W., Kim, J. W., Lee, C. H., and Rhee, C. S. (2017). Classification of chronic rhinosinusitis according to a nasal polyp and tissue eosinophilia: limitation of current classification system for Asian population. Asia Pac. Allergy 7:121. doi: 10.5415/apallergy.2017.7.3.121

Clark, D. W., Wenaas, A., Luong, A., Citardi, M. J., and Fakhri, S. (2013). Staphylococcus aureus prevalence in allergic fungal rhinosinusitis vs other subsets of chronic rhinosinusitis with nasal polyps. Int. Forum Allergy Rhinol. 3, 89-93. doi: 10.1002/alr.21090 
Cookson, W. (2004). The immunogenetics of asthma and eczema: a new focus on the epithelium. Nat. Rev. Immunol. 4, 978-988. doi: 10.1038/nri1500

Costenaro, L., Kaczmarska, Z., Arnan, C., Janowski, R., Coutard, B., Solà, M., et al. (2011). Structural basis for antiviral inhibition of the main protease, 3C, from human enterovirus 93. J. Virol. 85, 10764-10773. doi: 10.1128/JVI.05062-11

Coughlin, S. R., and Camerer, E. (2003). Participation in inflammation. J. Clin. Invest. 111, 25-27. doi: 10.1172/JCI17564

de Boer, J. D., van't Veer, C., Stroo, I., van der Meer, A. J., de Vos, A. F., van der Zee, J. S., et al. (2014). Protease-activated receptor-2 deficient mice have reduced house dust mite-evoked allergic lung inflammation. Innate Immun. 20, 618-625. doi: 10.1177/1753425913503387

DeConde, A. S., Mace, J. C., Levy, J. M., Rudmik, L., Alt, J. A., and Smith, T. L. (2017). Prevalence of polyp recurrence after endoscopic sinus surgery for chronic rhinosinusitis with nasal polyposis. Laryngoscope 127, 550-555. doi: 10.1002/lary.26391

Desrosiers, M. (2004). Refractory chronic rhinosinusitis: pathophysiology and management of chronic rhinosinusitis persisting after endoscopic sinus surgery. Curr. Allergy Asthma Rep. 4, 200-207. doi: 10.1007/s11882-004-0027-z

Ebert, C. S., McKinney, K. A., Urrutia, G., Wu, M., Rose, A. S., Fleischman, G. M., et al. (2014). Expression of protease-activated receptors in allergic fungal rhinosinusitis. Int. Forum Allergy Rhinol. 4, 266-271. doi: 10.1002/alr.21295

Feldman, R. E., Lam, A. C., Sadow, P. M., and Bleier, B. S. (2013). P-glycoprotein is a marker of tissue eosinophilia and radiographic inflammation in chronic rhinosinusitis without nasal polyps. Int. Forum Allergy Rhinol. 3, 684-687. doi: $10.1002 /$ alr. 21176

Fokkens, W. J., Lund, V. J., Mullol, J., Bachert, C., Alobid, I., Baroody, F., et al. (2012). EPOS 2012: European position paper on rhinosinusitis and nasal polyps 2012. A summary for otorhinolaryngologists. Rhinology 50, 1-12. doi: 10.4193/Rhino50E2

Fokkens, W., Lund, V., Bachert, C., Clement, P., Helllings, P., Holmstrom, M., et al. (2005). EAACI position paper on rhinosinusitis and nasal polyps executive summary. Allergy 60, 583-601. doi: 10.1111/j.1398-9995.2005.00830.x

Gregory, L. G., and Lloyd, C. M. (2011). Orchestrating house dust mite-associated allergy in the lung. Trends Immunol. 32, 402-411. doi: 10.1016/j.it.2011.06.006

Hammad, H., Chieppa, M., Perros, F., Willart, M. A., Germain, R. N., and Lambrecht, B. N. (2009). House dust mite allergen induces asthma via tolllike receptor 4 triggering of airway structural cells. Nat. Med. 15, 410-416. doi: 10.1038/nm.1946

Hammad, H., and Lambrecht, B. N. (2015). Barrier epithelial cells and the control of type 2 immunity. Immunity 43, 29-40. doi: 10.1016/j.immuni.2015.07.007

Hara, K., Iijima, K., Elias, M. K., Seno, S., Tojima, I., Kobayashi, T., et al. (2014). Airway uric acid is a sensor of inhaled protease allergens and initiates type 2 immune responses in respiratory mucosa. J. Immunol. 192, 4032-4042. doi: 10.4049/jimmunol.1400110

Hershenson, M. B. (2007). Proteases and protease-activated receptors signalling: at the crossroads of acquired and innate immunity. Clin. Exp. Allergy 37, 963-966. doi: 10.1111/j.1365-2222.2007.02738.x

Hirasawa, Y. (2010). Staphylococcus aureus extracellular protease causes epidermal barrier dysfunction. J. Invest. Dermat. 130, 614-617. doi: 10.1038/jid.2009.257

Huang, L., Wring, S. A., Woolley, J. L., Brouwer, K. R., Serabjit-Singh, C., and Polli, J. W. (2001). Induction of P-glycoprotein and cytochrome P450 3A by HIV protease inhibitors. Drug Metabol. Disposition 29, 754-760.

Ikeda, K., Shiozawa, A., Ono, N., Kusunoki, T., Hirotsu, M., Homma, H., et al. (2013). Subclassification of chronic rhinosinusitis with nasal polyp based on eosinophil and neutrophil. Laryngoscope 123, E1-E9. doi: 10.1002/lary.24154

Jacquet, A. (2011). Interactions of airway epithelium with protease allergens in the allergic response. Clin. Exp. Allergy 41, 305-311. doi: 10.1111/j.1365-2222.2010.03661.x

Kale, S. L., Agrawal, K., Gaur, S. N., and Arora, N. (2017). Cockroach protease allergen induces allergic airway inflammation via epithelial cell activation. Sci Rep. 7:42341. doi: 10.1038/srep42341

Kamijo, S., Takeda, H., Tokura, T., Suzuki, M., Inui, K., Hara, M., et al. (2013). IL-33-mediated innate response and adaptive immune cells contribute to maximum responses of protease allergen-induced allergic airway inflammation. J. Immunol. 190, 4489-4499. doi: 10.4049/jimmunol.1201212

Kesic, M. J., Hernandez, M., and Jaspers, I. (2012). Airway protease/antiprotease imbalance in atopic asthmatics contributes to increased Influenza A virus cleavage and replication. Respir. Res. 13:82. doi: 10.1186/1465-9921-13-82
Kheradmand, F., Kiss, A., Xu, J., Lee, S. H., Kolattukudy, P. E., and Corry, D. B. (2002). A protease-activated pathway underlying Th cell type 2 activation and allergic lung disease. J. Immunol. 169, 5904-5911. doi: 10.4049/jimmunol.169.10.5904

Kim, D. Y., Cho, S. H., Takabayashi, T., and Schleimer, R. P. (2015). Chronic rhinosinusitis and the coagulation system. Allergy Asthma Immunol. Res. 7, 421-430. doi: 10.4168/aair.2015.7.5.421

Kim, J.-W., Hong, S. L., Kim, Y. K., Lee, C. H., Min, Y. G., and Rhee, C. S. (2007) Histological and immunological features of non-eosinophilic nasal polyps. Otolaryngol. Head Neck Surg. 137, 925-930. doi: 10.1016/j.otohns.2007.07.036

Kouzaki, H., Matsumoto, K., Kato, T., Tojima, I., Shimizu, S., and Shimizu, T. (2016). Epithelial cell-derived cytokines contribute to the pathophysiology of eosinophilic chronic rhinosinusitis. J. Interferon. Cytokine Res. 36, 169-179. doi: 10.1089/jir.2015.0058

Kouzaki, H., Matsumoto, K., Kikuoka, H., Kato, T., Tojima, I., Shimizu, S., et al. (2017). Endogenous protease inhibitors in airway epithelial cells contribute to eosinophilic chronic rhinosinusitis. Am. J. Respir. Crit. Care Med. 195, 737-747. doi: 10.1164/rccm.201603-0529OC

Lambrecht, B. N., and Hammad, H. (2013). Asthma and coagulation. N. Engl. J. Med. 369, 1964-1966. doi: 10.1056/NEJMcibr1311045

Lan, F., Zhang, N., Gevaert, E., Zhang, L., and Bachert, C. (2016). Viruses and bacteria in Th2-biased allergic airway disease. Allergy 71, 1381-1392. doi: $10.1111 /$ all.12934

Madeo, J., and Frieri, M. (2013). Bacterial biofilms and chronic rhinosinusitis. Allergy Asthma Proc. 34, 335-341. doi: 10.2500/aap.2013.34.3665

Meaden, E. R., Hoggard, P. G., Newton, P., Tjia, J. F., Aldam, D., Cornforth, D., et al. (2002). P-glycoprotein and MRP1 expression and reduced ritonavir and saquinavir accumulation in HIV-infected individuals. J. Antimicrob. Chemother. 50, 583-588. doi: 10.1093/jac/dkf161

Mendelsohn, D., Jeremic, G., Wright, E. D., and Rotenberg, B. W. (2011). Revision rates after endoscopic sinus surgery: a recurrence analysis. Ann. Otol. Rhinol. Laryngol. 120, 162-166. doi: 10.1177/000348941112000304

Millien, V. O., Lu, W., Shaw, J., Yuan, X., Mak, G., Roberts, L., et al. (2013). Cleavage of fibrinogen by proteinases elicits allergic responses through Toll-like receptor 4. Science 341, 792-796. doi: 10.1126/science.1240342

Moffatt, M. (2004). SPINK5: a gene for atopic dermatitis and asthma. Clin. Exp. Allergy 34, 325-327. doi: 10.1111/j.1365-2222.2004.01915.x

Mortuaire, G., Leroy, X., Gengler, I., Chevalier, D., Prin, L., and Picry, A. (2015). Histopathological classification of refractory chronic rhinosinusitis with nasal polyps. Histol. Histopathol. 30, 1447-1454. doi: 10.14670/HH-11-632

Orlandi, R. R., Kingdom, T. T., Hwang, P. H., Smith, T. L., Alt, J. A., Baroody, F. M., et al. (2016). International consensus statement on allergy and rhinology: rhinosinusitis. Int. Forum Allergy Rhinol. 6(Suppl. 1), S22-S209. doi: 10.1002/alr.21695

Ou, J., Wang, J., Xu, Y., Tao, Z. Z., Kong, Y. G., Chen, S.-M., et al. (2014). Staphylococcus aureus superantigens are associated with chronic rhinosinusitis with nasal polyps: a meta-analysis. Eur. Arch. Otorhinolaryngol. 271, 2729-2736. doi: 10.1007/s00405-014-2955-0

Perloff, M. D., von Moltke, L. L., Fahey, J. M., Daily, J. P., and Greenblatt, D. J. (2000). Induction of P-glycoprotein expression by HIV protease inhibitors in cell culture. Aids 14, 1287-1289. doi: 10.1097/00002030-200006160-00034

Pfeffer, P. E., and Corrigan, C. J. (2017). An imbalance between proteases and endogenous protease inhibitors in eosinophilic airway disease. Am. J. Respir. Crit. Care Med. 195, 707-708. doi: 10.1164/rccm.2016102020ED

Reed, C. E., and Kita, H. (2004). The role of protease activation of inflammation in allergic respiratory diseases. J. Allergy Clin. Immunol. 114, 997-1008. doi: $10.1016 /$ j.jaci.2004.07.060

Runswick, S., Mitchell, T., Davies, P., Robinson, C., and Garrod, D. R. (2007). Pollen proteolytic enzymes degrade tight junctions. Respirology 12, 834-842. doi: 10.1111/j.1440-1843.2007.01175.x

Sachse, F., Becker, K., Von Eiff, C., Metze, D., and Rudack, C. (2010). Staphylococcus aureus invades the epithelium in nasal polyposis and induces IL-6 in nasal epithelial cells in vitro. Allergy 65, 1430-1437. doi: 10.1111/j.1398-9995.2010.02381.x

Schleimer, R. P. (2017). Immunopathogenesis of chronic rhinosinusitis and nasal polyposis. Annu. Rev. Pathol. 12, 331-357. doi: 10.1146/ annurev-pathol-052016-100401 
Schleimer, R. P., and Berdnikovs, S. (2017). Etiology of epithelial barrier dysfunction in patients with type 2 inflammatory diseases. J. Allergy Clin. Immunol. 139, 1752-1761. doi: 10.1016/j.jaci.2017.04.010

Shah, S. A., Ishinaga, H., and Takeuchi, K. (2016). Pathogenesis of eosinophilic chronic rhinosinusitis. J. Immunol. 13:11. doi: 10.1186/s12950-016-0121-8

Shikani, A. H., Sidhaye, V. K., Basaraba, R. J., Shikani, H. J., Alqudah, M. A., Kirk, N., et al. (2014). Mucosal expression of aquaporin 5 and epithelial barrier proteins in chronic rhinosinusitis with and without nasal polyps. Am. J. Otolaryngol. 35, 377-383. doi: 10.1016/j.amjoto.2013.11.011

Shimizu, S., Gabazza, E. C., Ogawa, T., Tojima, I., Hoshi, E. H., Kouzaki, et al. (2011). Role of thrombin in chronic rhinosinusitis-associated tissue remodeling. Am. J. Rhinol. Allergy 25, 7-11. doi: 10.2500/ajra.2011.25.3535

Shin, S.-H., and Lee, Y. H. (2010). Airborne fungi induce nasal polyp epithelial cell activation and toll-like receptor expression. Int. Arch. Allergy Immunol. 153, 46-52. doi: 10.1159/000301578

Shin, S.-H., Lee, Y. H., and Jeon, C. H. (2006). Protease-dependent activation of nasal polyp epithelial cells by airborne fungi leads to migration of eosinophils and neutrophils. Acta Otolaryngol. 126, 1286-1294. doi: 10.1080/00016480500395179

Snelgrove, R. J., Gregory, L. G., Peiró, T., Akthar, S., Campbell, G. A., Walker, S. A., et al. (2014). Alternaria-derived serine protease activity drives IL-33mediated asthma exacerbations. J. Allergy Clin. Immunol. 134, 583-592.e6. doi: 10.1016/j.jaci.2014.02.002

Sokol, C. L., Barton, G. M., Farr, A. G., and Medzhitov, R. (2008). A mechanism for the initiation of the Th2 response by an allergen. Nat. Immunol. 9, 310-318. doi: $10.1038 /$ ni1558

Stentzel, S., Teufelberger, A., Nordengrün, M., Kolata, J., Schmidt, F., van Crombruggen, K., et al. (2017). Staphylococcal serine protease-like proteins are pacemakers of allergic airway reactions to Staphylococcus aureus. J. Allergy Clin. Immunol. 139, 492-500.e8. doi: 10.1016/j.jaci.2016.03.045

Stevens, W. W., Peters, A. T., Hirsch, A. G., Nordberg, C. M., Schwartz, B. S., Mercer, D. G., et al. (2017). Clinical characteristics of patients with chronic rhinosinusitis with nasal polyps, asthma, and aspirin-exacerbated respiratory disease. J. Allergy Clin. Immunol. Pract. 5, 1061-1070.e3. doi: 10.1016/j.jaip.2016.12.027

Ta, V., and White, A. A. (2015). Survey-defined patient experiences with aspirinexacerbated respiratory disease. J. Allergy Clin. Immunol. Pract. 3, 711-718. doi: 10.1016/j.jaip.2015.03.001

Tai, H. Y., Tam, M., Chou, H., Peng, H. J., Su, S. N., Perng, D. W., et al. (2006). Pen ch 13 allergen induces secretion of mediators and degradation of occludin protein of human lung epithelial cells. Allergy 61, 382-388. doi: $10.1111 / j .1398-9995.2005 .00958 . x$

Takai, T., and Ikeda, S. (2011). Barrier dysfunction caused by environmental proteases in the pathogenesis of allergic diseases. Allergol Int. 60, 25-35. doi: 10.2332/allergolint.10-RAI-0273

Teufelberger, A. R., Nordengrün, M., Braun, H., Maes, T., De Grove, K., Holtappels, G., et al. (2017). The IL-33/ST2 axis is crucial in type 2 airway responses induced by the Staphylococcus aureus-derived serine protease-like protein D. J. Allergy Clin. Immunol. doi: 10.1016/j.jaci.2017.05.004. [Epub ahead of print].

Tieu, D. D., Kern, R. C., and Schleimer, R. P. (2009). Alterations in epithelial barrier function and host defense responses in chronic rhinosinusitis. J. Allergy Clin. Immunol. 124, 37-42. doi: 10.1016/j.jaci.2009.04.045

Tipirneni, K. E., and Woodworth, B. A. (2017). Medical and surgical advancements in the management of cystic fibrosis chronic rhinosinusitis. Curr. Otorhinolaryngol. Rep. 5, 24-34. doi: 10.1007/s40136-017-0139-3

Tomassen, P., Vandeplas, G., Van Zele, T., Cardell, L. O., Arebro, J.,Olze, H., et al. (2016). Inflammatory endotypes of chronic rhinosinusitis based on cluster analysis of biomarkers. J. Allergy Clin. Immunol. 137, 1449-1456.e4. doi: 10.1016/j.jaci.2015.12.1324

Tosun, F., Arslan, H. H., Karslioglu, Y., Deveci, M. S., and Durmaz, A. (2010). Relationship between postoperative recurrence rate and eosinophil density of nasal polyps. Ann. Otol. Rhinol. Laryngol. 119, 455-459. doi: $10.1177 / 000348941011900705$

Van Zele, T., Claeys, S., Gevaert, P., Van Maele, G., Holtappels, G., Van Cauwenberge,. P., et al. (2006). Differentiation of chronic sinus diseases by measurement of inflammatory mediators. Allergy 61, 1280-1289. doi: 10.1111/j.1398-9995.2006.01225.x

Verma, S., Dixit, R., and Pandey, K. C. (2016). Cysteine proteases: modes of activation and future prospects as pharmacological targets. Front. Pharmacol. 7:107. doi: 10.3389/fphar.2016.00107

Wan, H., Winton, H. L., Soeller, C., Tovey, E. R., Gruenert, D. C., Thompson, P. J., et al. (1999). Der $\mathrm{p} 1$ facilitates transepithelial allergen delivery by disruption of tight junctions. J. Clin. Invest. 104, 123-133. doi: 10.1172/JCI5844

Wan, H., Winton, H. L., Soeller, C., Taylor, G. W., Gruenert, D. C., Thompson, P. J., et al. (2001). The transmembrane protein occludin of epithelial tight junctions is a functional target for serine peptidases from faecal pellets of Dermatophagoides pteronyssinus. Clin. Exp. Allergy 31, 279-294. doi: 10.1046/j.1365-2222.2001.00970.x

Wu, D., Li, L., Zhang, M., Wang, J., and Wei, Y. (2017). Two inflammatory phenotypes of nasal polyps and comorbid asthma. Ann. Allergy Asthma Immunol. 118, 318-325. doi: 10.1016/j.anai.2016.12.018

Wu, D., Wang, J., and Zhang, M. (2016). Altered Th17/Treg ratio in nasal polyps with distinct cytokine profile: association with patterns of inflammation and mucosal remodeling. Medicine 95:e2998. doi: 10.1097/MD.0000000000 00299

Wynn, R., and Har-El, G. (2004). Recurrence rates after endoscopic sinus surgery for massive sinus polyposis. Laryngoscope 114, 811-813. doi: 10.1097/00005537-200405000-00004

Zastre, J. A., Chan, G. N., Ronaldson, P. T., Ramaswamy, M., Couraud, P. O., Romero, I. A., et al. (2009). Up-regulation of P-glycoprotein by HIV protease inhibitors in a human brain microvessel endothelial cell line. J. Neurosci. Res. 87, 1023-1036. doi: 10.1002/jnr.21898

Zhang, N., Van Zele, T., Perez-Novo, C., Van Bruaene, N., Holtappels, G., DeRuyck, N., et al. (2008). Different types of T-effector cells orchestrate mucosal inflammation in chronic sinus disease. J. Allergy Clin. Immunol. 122, 961-968. doi: 10.1016/j.jaci.2008.07.008

Zhang, Y., and Benet, L. Z. (1998). Characterization of P-glycoprotein mediated transport of $\mathrm{K} 02$, a novel vinylsulfone peptidomimetic cysteine protease inhibitor, across MDR1-MDCK and Caco-2 cell monolayers. Pharm Res. 15, 1520-1524. doi: 10.1023/A:10119907 30230

Conflict of Interest Statement: The senior author has a patent related to P-gp modulation in CRSwNP.

The other authors declare that the research was conducted in the absence of any commercial or financial relationships that could be construed as a potential conflict of interest.

Copyright $\odot 2018 \mathrm{Wu}$, Wei and Bleier. This is an open-access article distributed under the terms of the Creative Commons Attribution License (CC BY). The use, distribution or reproduction in other forums is permitted, provided the original author(s) or licensor are credited and that the original publication in this journal is cited, in accordance with accepted academic practice. No use, distribution or reproduction is permitted which does not comply with these terms. 